\title{
THREE-PHASE SHUNT ACTIVE POWER LINE CONDITIONER
}

\author{
A. A. Mansour ${ }^{(1)}$, A. M. Zaki ${ }^{(2)}$, O. A. Mahgoub ${ }^{(3)}$, E. E. Abu-Elzahab ${ }^{(4)}$ \\ ${ }^{1,2)}$ Electronics Research Institute, El-Tahrir street, Dokki, Cairo, Egypt \\ ${ }^{3,4)}$ Department of Electrical Power \& Machines, Cairo University Giza, Egypt
}

\begin{abstract}
The shunt Active Power Line Conditioners represent one of the advanced techniques used to overcome the harmonic currents drawn by the non-linear loads because of their fast dynamic performance in harmonics compensation. This paper introduces the harmonics extraction applying the Average Control Technique based on the $\mathrm{d}-\mathrm{q}$ reference frame. The technique is achieved through both simulation and experimental implementation.
\end{abstract}

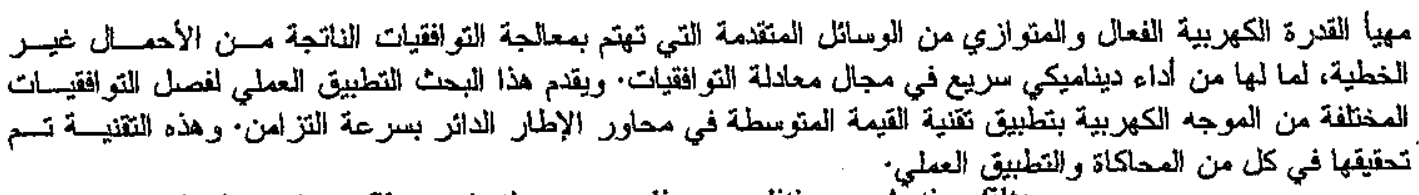
Keywords: Active power filters, Active power line conditioner, Active filters.

\section{INTRODUCTION}

Due to the enhancement in the power electronics technology, modern control systems have been established such as variable speed drives, converter circuits, personal computers, Static VAR Compensators (SVC), and many other loads based on power semiconductor circuits. The previous loads play an important role in increasing harmonics in the electric power networks. So the power quality suffers and degrades due to the presence of these harmonics which represent an incessant distortion in both voltages and currents in the electric network.

Increasing the harmonic levels means more troubles in the electric grid. The problems arising from harmonics can be epitomized in, increasing the RMS current and excessive neutral currents. The previous drawbacks will lead to incessant heating of the electrical equipments such as transformers and supply apparatus, resonance causes over stress of power factor capacitors, trip of circuit breakers (i.e. blinding their operation), malfunction of phase locked loop circuits, and communication interference. So, the term power quality and its related harmonics problems have gained much attention. Solving the harmonics problems can be achieved using different techniques according to the harmonics compensation requirements.

Different techniques can be used to compensate the harmonics: Passive filters and Active Power Filters (APF's). Active Power Filters are now mature and can be classified as shunt, series, and universal APF's $[1,2]$.
The extraction of the harmonic current reference is the first step in the compensation process. This can be achieved by different techniques in the frequency domain such as Fast Fourier Transform (FFT) on the time domain such as $\mathrm{p}-\mathrm{q}$ transformation or $\mathrm{d}-\mathrm{q}$ reference frame [3-6].

This paper studies the shunt three-phase APF as shown in Fig. 1. The control strategy is based on the $d-q$ reference frame using the Average Control Technique to extract the harmonic current reference then applying the hystersis current controller for closed loop implementation. There is no need for a previous knowledge about the harmonic equations of the load current since this technique splits only the fundamental component from the load current and the remainder represents the total harmonics content of the load.

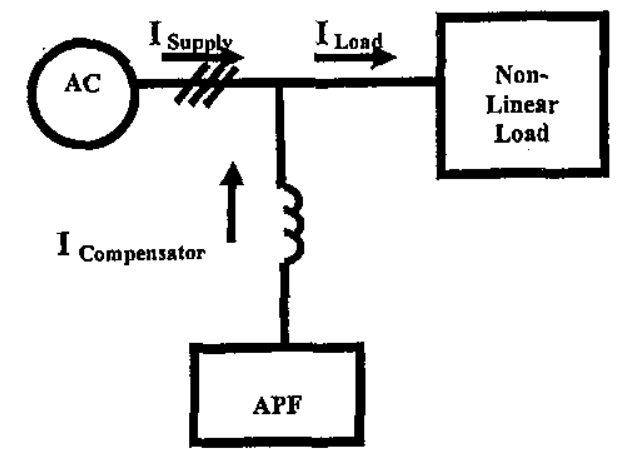

Fig. 1. Three-Phase Shunt APF. 


\section{THE AVERAGE CONTROL TECHNIQUE}

The transformation from three-phase three-wire system to the $d-q$ reference frame is helpful in decoupling the variables used in the control action into two components the direct and quadrature components as in (1).

$$
\left[\begin{array}{c}
v_{d} \\
v_{q} \\
0
\end{array}\right]=C 1\left[\begin{array}{l}
v_{a} \\
v_{b} \\
v_{c}
\end{array}\right]
$$

where,

$$
C 1=\frac{2}{3}\left[\begin{array}{ccc}
\operatorname{Cos} \theta & \operatorname{Cos}\left(\theta \frac{2 \pi}{3}\right) & \operatorname{Cos}\left(\theta+\frac{2 \pi}{3}\right) \\
-\operatorname{Sin} \theta & -\operatorname{Sin}\left(\theta \frac{2 \pi}{3}\right) & -\operatorname{Sin}\left(\theta+\frac{2 \pi}{3}\right) \\
\frac{1}{\sqrt{2}} & \frac{1}{\sqrt{2}} & \frac{1}{\sqrt{2}}
\end{array}\right]
$$

$\theta$ is the transformation angle.

It is known that for any transformation to the $d-q$ reference frame rotating with the synchronous rotating speed, the vector components appears as dc components in the d-q rotating frame. So a question, arises: what about the other components that rotates with speeds of integer multiples of the fundamental? i.e. the harmonic components.

Figure 2 shows the representation in the stationary frame for a voltage vector consisting of two components as follows: $v_{(t)}=\sin \left(\omega_{s} t\right)+0.2 \sin \left(5 \omega_{s} t\right)$. Since the $5^{\text {th }}$ harmonic component is a negative sequence component so, the relative speed $\omega_{\text {relative }}$ between the two vectors (i.e. the fundamental and the $\left.5^{\text {th }}\right)$ will be $\omega_{\text {relative }}=\omega_{s}-\left(-5 \omega_{s}\right)=6 \omega_{s}$. So the $5^{\text {th }}$ harmonic rotates with $6 \omega_{s}$ w.r.t the fundamental in the $\mathrm{d}-\mathrm{q}$ reference frame. It is shown that the overall vector deviates from the locus of the circle that represents the fundamental component.

Applying the transformation to the $\mathrm{d}-\mathrm{q}$ reference frame, the $5^{\text {th }}$ harmonic appears as both cosine and sine waves in the $d$ and $q$ components as shown in Fig. 3, and having six complete cycles along one cycle of the fundamental. So, any order of harmonics appears as sinusoidal wave in the $d-q$ reference frame. The average of complete cycles of sine waves equal to zero. Hence, tacking the average in the $d-q$ reference frame splits the fundamental component in the $d-q$ frame from the harmonic content of the original wave. Splitting the harmonics from the distorted wave in the $\mathrm{d}-\mathrm{q}$ reference frame is achieved based on the average algorithm called the Average Control Technique [4].

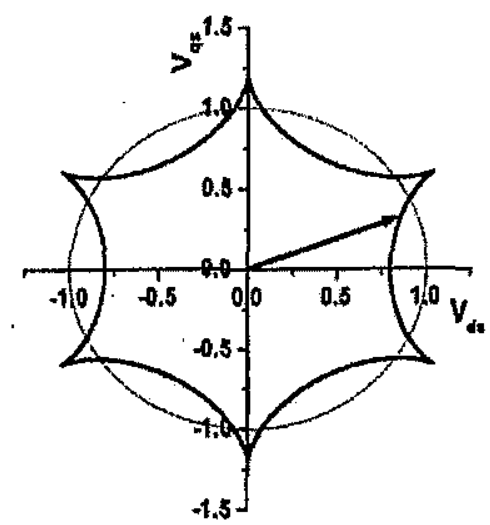

Fig. 2. Three-phase fundamental signal plus 0.2 P.U. $5^{\text {th }}$ harmonic in stationary frame.

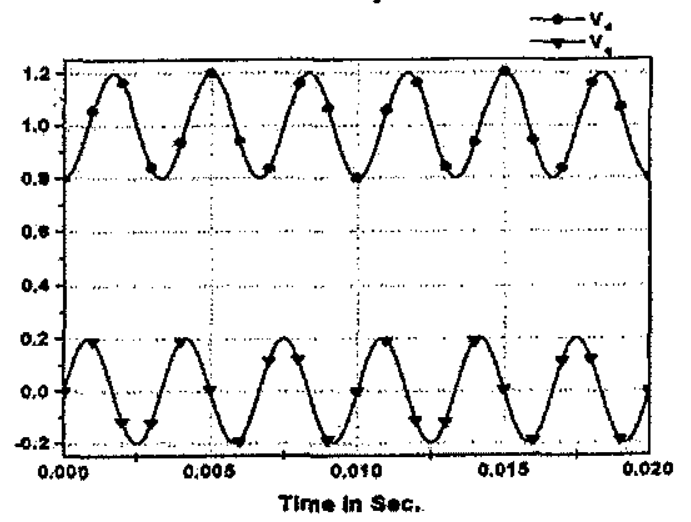

Fig. 3. Three-phase fundamental signal plus 0.2 p.u. $5^{\text {th }}$ harmonic in rotating reference frame.

\section{SIMULATION RESULTS}

The simulation program has been performed using MATLAB software package. The closed loop simulation program of the APF has been performed for only R-C load fed from three-phase rectifier bridge as individual load and a general non-linear load as shown in Fig. 4 which consists of three parallel loads, threephase linear inductive load, three-phase rectifier bridge feeding R-L load, and three-phase rectifier bridge feeding R-C load.

For three-phase rectifier bridge feeding $\mathrm{R}-\mathrm{C}$ load, where $\mathrm{C}=200 \mu \mathrm{F}, \mathrm{R}=150 \Omega$, and the supply voltage equal to 380 volt. Figure 5 , shows the line load current drawn by the load $i_{R-\text { Lad }}$ The THD of this load current equal to $104 \%$.

Applying the Average Control Technique to the previous wave in the $d-q$ reference frame gives the harmonic content $i_{h \text {-Load }}$ as shown in Fig. 6. 


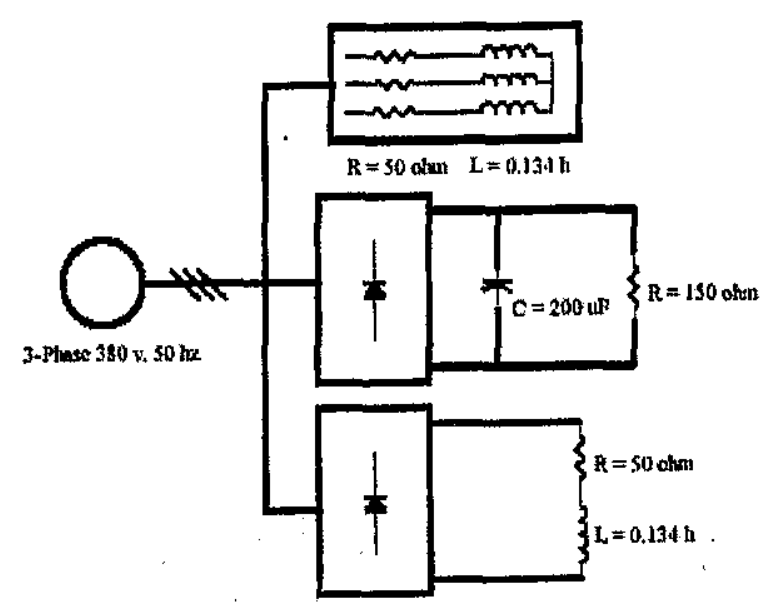

Fig. 4. Power circuit for the general load.

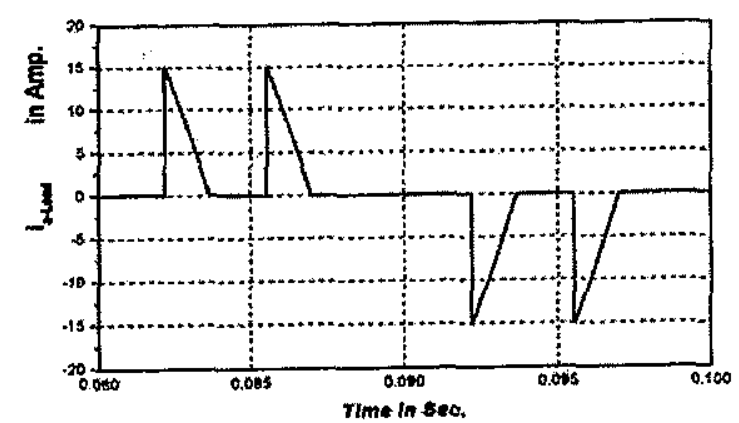

Fig. 5. Line current drawn by the load.

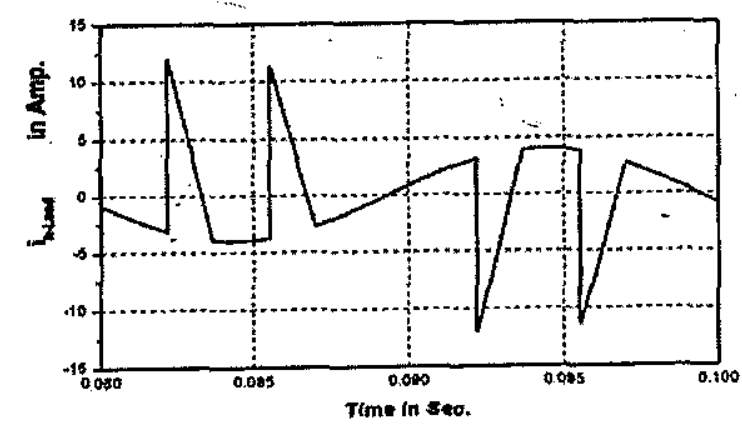

Fig. 6. The harmonic current contents of the load.

Using the extracted harmonic waveform to control the APF to inject equal and anti-phase waveform using the hystresis current controller. The supply current appears as a sinusoidal wave as shown in Fig. 7, except for some spikes. These spikes appears because the supply inductance feeding the load is neglected and the APF is connected to $A C$ mains through an inductor, so the compensation will be limited at the sharp transitions. The THD of the supply current is reduced to $13.2 \%$.

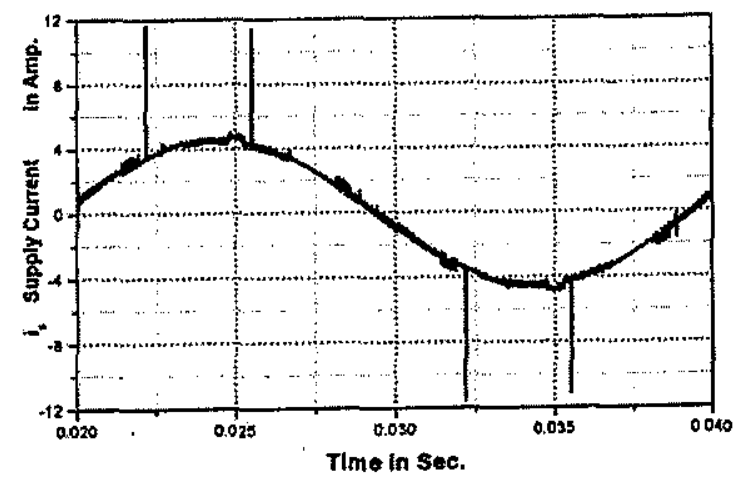

Fig. 7. Supply current after compensation.

For general non-linear load the drawn line current is shown in Fig. 8, with $\mathrm{THD}=46 \%$.. This load consists of two individual $\mathrm{R}-\mathrm{C}$ and $\mathrm{R}-\mathrm{L}$ feeding from three-phase rectifier bridge and another linear $\mathrm{R}-\mathrm{L}$ load shown in Fig. 4.

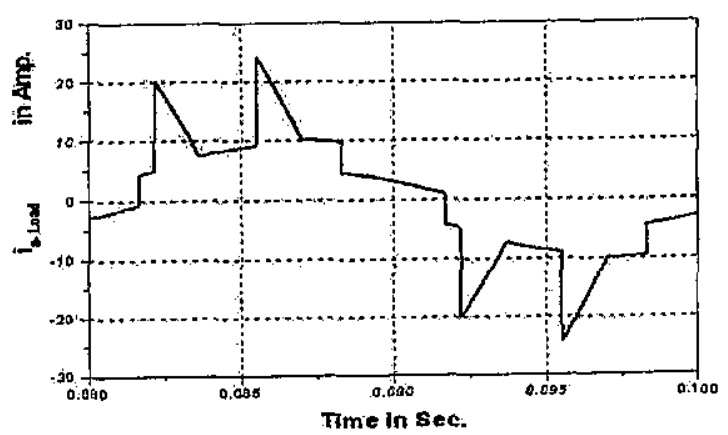

Fig. 8. Line load current.

Figure 9, shows the harmonic contents of this load current. After harmonic compensation the THD of the supply current shown in Fig. 10, is reduced to $4 \%$.

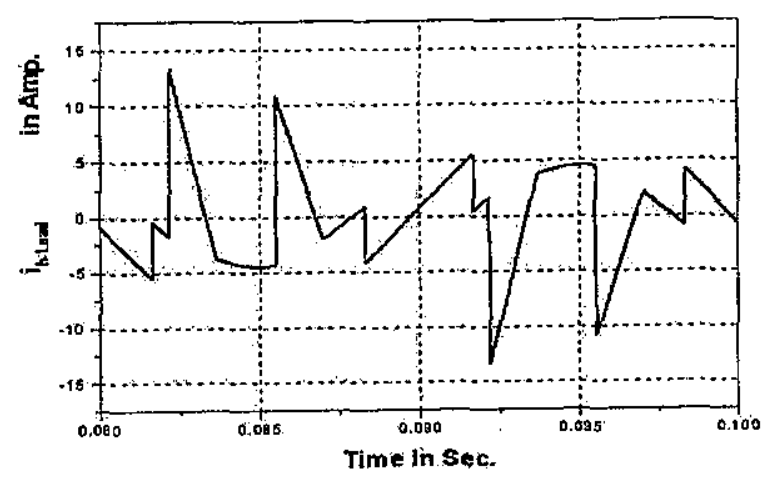

Fig. 9. The harmonic current contents of the load. 


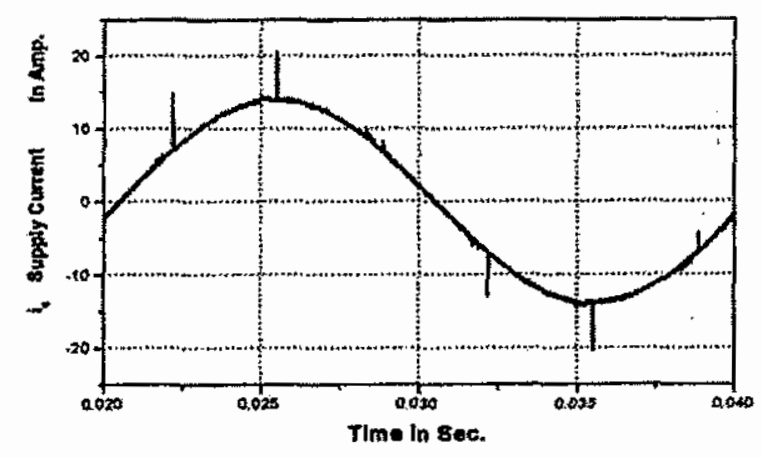

Fig.10. Supply current after compensation.

\section{EXPERIMENTAL RESULTS}

Figure 11 shows the closed-loop system block diagram for harmonics compensation. The inductor of the APF has an inductance $\mathrm{L}$ equal to $116(\mu \mathrm{H})$ and the dc capacitor link $\mathrm{C}$ equal to $3250(\mu \mathrm{F})$ to make the DC link voltage is nearly constant.

Since the scope signals are in voltage scale, then every current reading referred to the voltage scale is calculated using equation (2) which represents the calibrated current sensor equation as:

$$
\mathrm{i}=0.2278+2.8678 \times \mathrm{v}_{\text {sensor }} \text { Amp }
$$
where $v_{\text {sensor }}$ is the output voltage of the current sensor.
For three-phase rectifier bridge feeding only the R-C load shown in Fig. 11 with load parameters as follows $R=6.2 \Omega$, and $C=350 \mu \mathrm{F}$. Figure 12 , shows the drawn line current by the load on channel 1, and channel 2 . Also, the extracted harmonic content of both line $A$, and line $B$ on channels 3,4 .

Figure 13, shows the harmonic compensation for the load current appears on channel $R 1$, the supply voltage on channel 1 , and the supply current on last channel 3 . The APF can be used to correct the fundamental power factor by adding the fundamental reactive component to the control signal used to control the APF. The supply current after compensating both harmonics and reactive component is appeared in Fig. 14 on channel 3 where its ground coincides the same ground of the supply voltage on appeared on channel 1 . The supply current has a good power factor than that appeared in Fig. 13.

Another general load introduces three parallel threephase load as shown in Fig. 12. Figure 15, shows the line load currents on channel 1 , and channel 2 . The extracted harmonics for line $\mathrm{A}$ and line $\mathrm{B}$ on channels 3 ,4. Figure 16, shows the load current on channel R1, the supply voltage on channel 1 , and the supply current on channel 3. a sinusoidal supply current is achieved. Adding the fundamental reactive current signal component to achieve power factor correction, The supply current appeared in Fig. 17 on channel 3 has a good power factor than that appeared in Fig. 16.

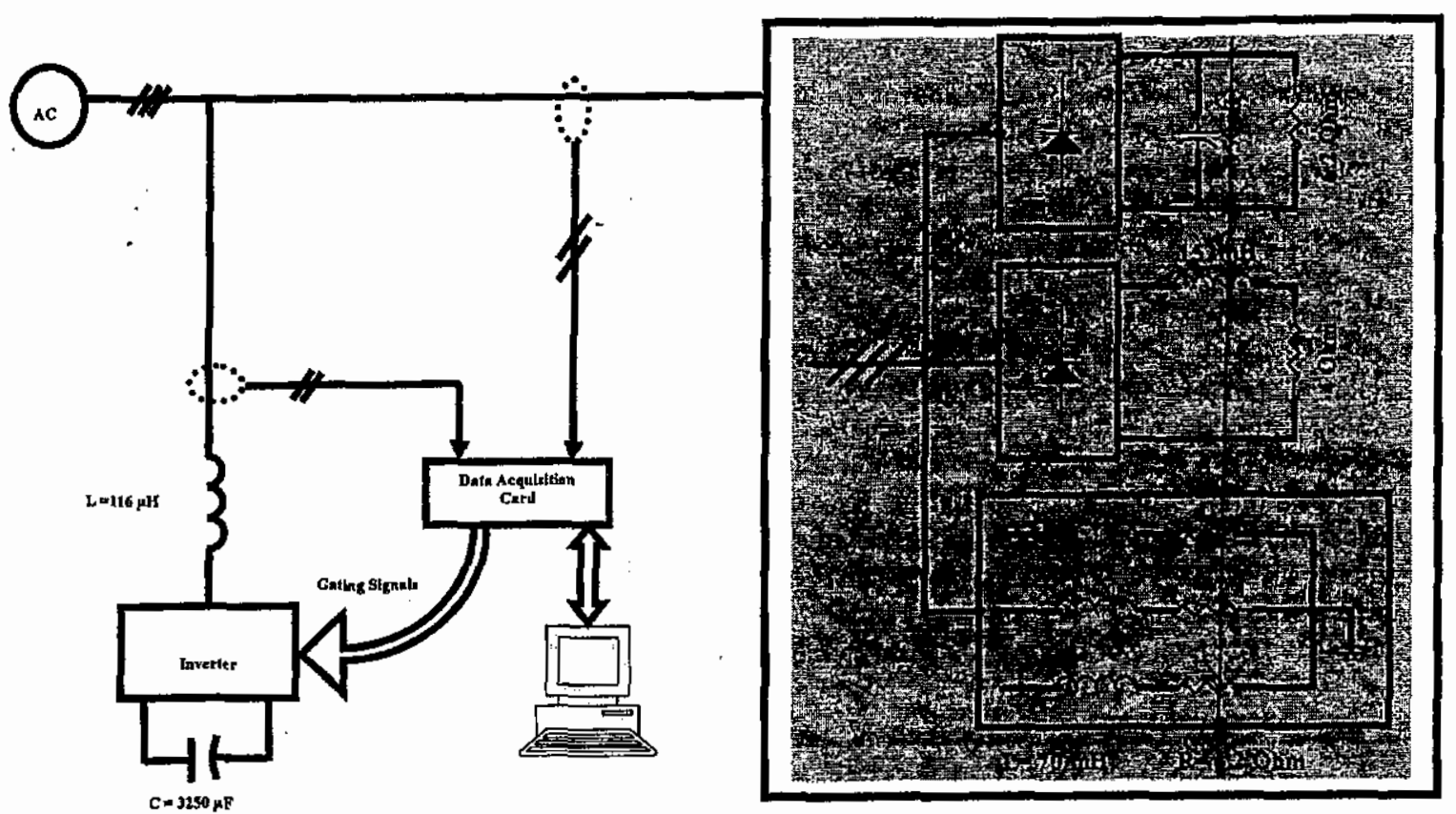

Fig.11. Experimental Circuit. 


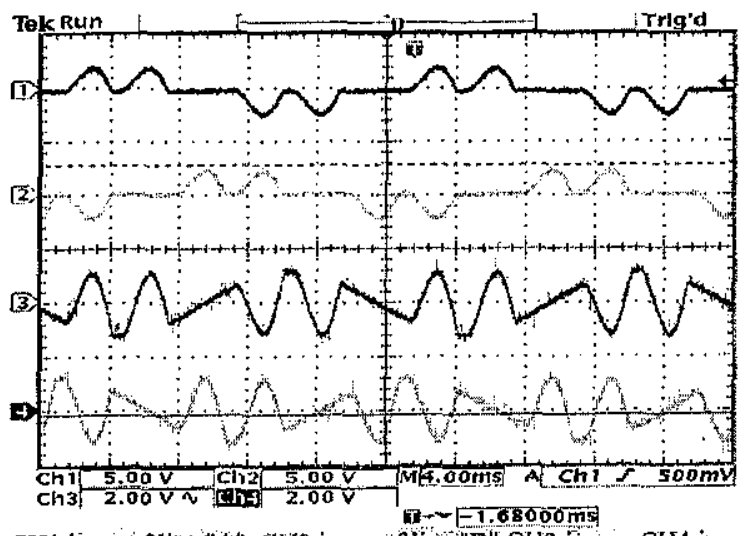

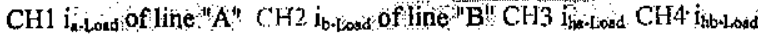

Fig.12. The $i_{a-L o a d}, i_{\text {ha-load }}$ and $i_{h b-l o a d}$ in three-phase system

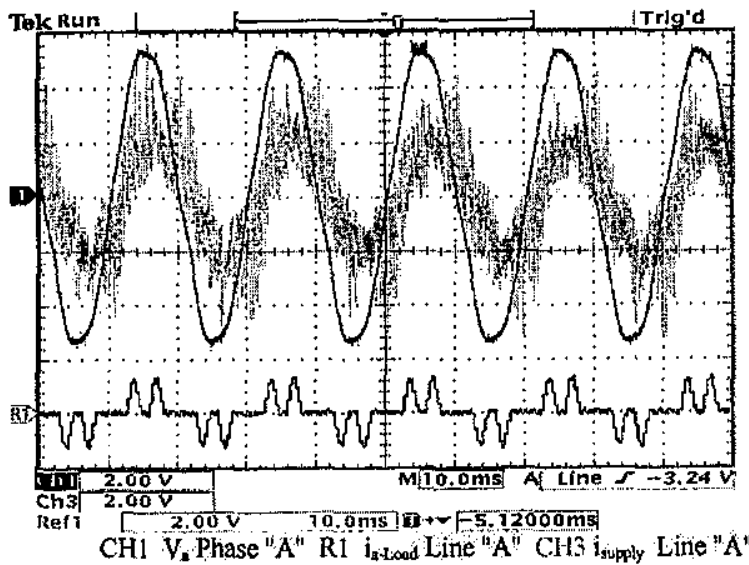

Fig.13. Harmonic compensation for R-C load fed from rectifier bridge.

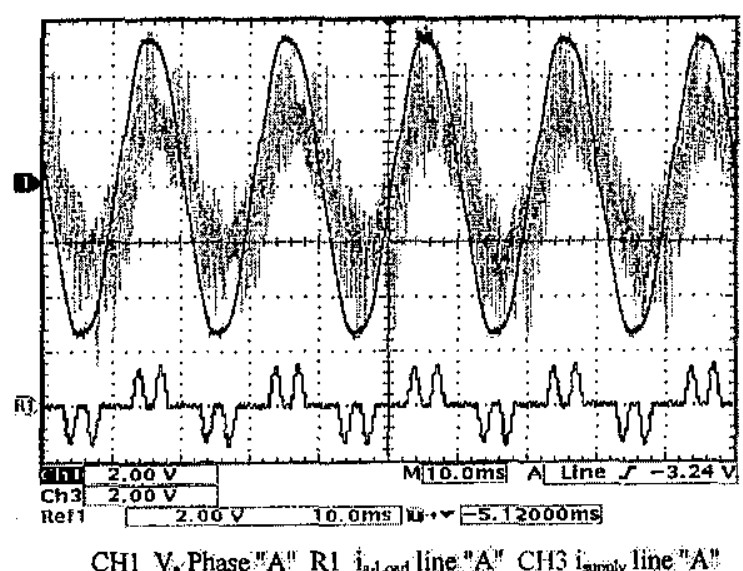

Fig.14. Harmonic compensation and power factor correction.

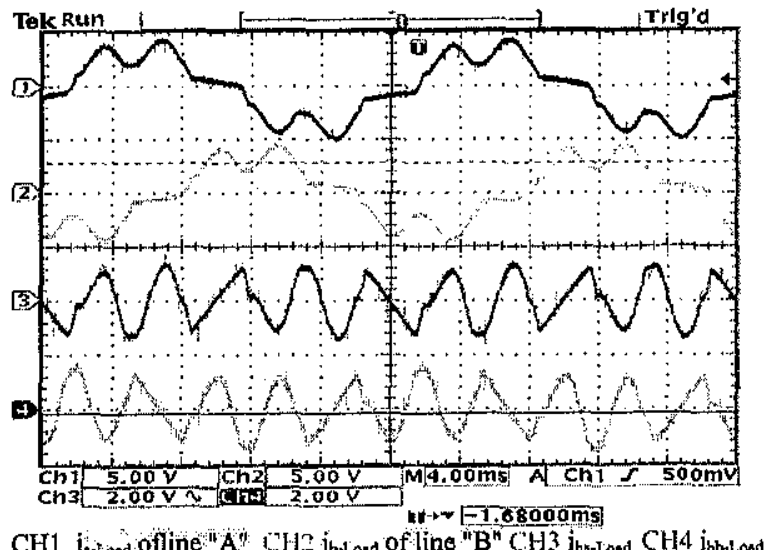

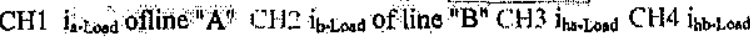

Fig.15. The $i_{a-L o a d}, i_{\text {ha-load }}$ and $i_{h b-l o a d}$

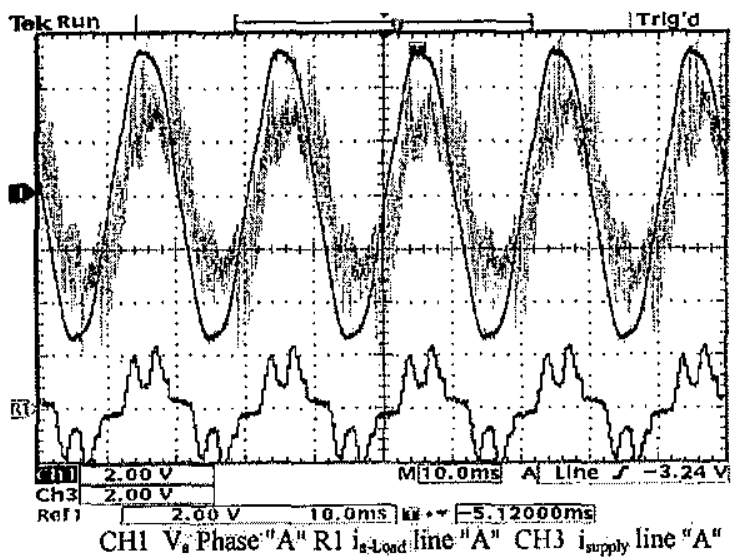

Fig, 16. Harmonic compensation only.

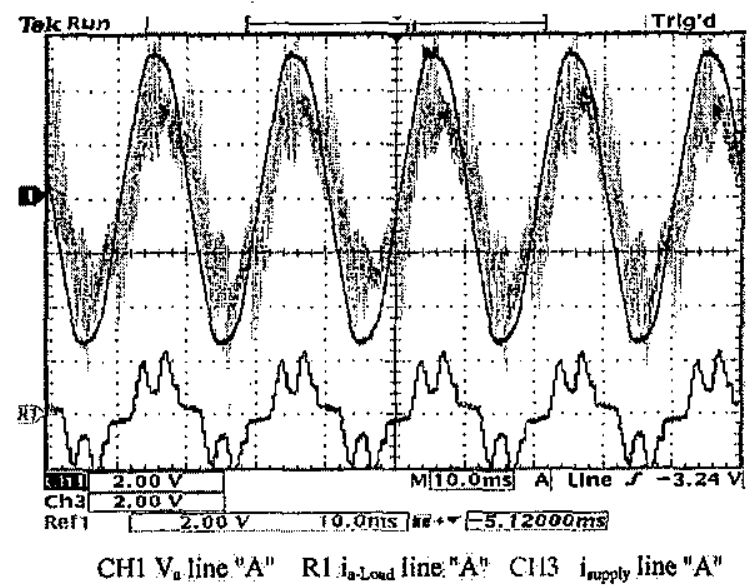

Fig. 17. Harmonic compensation and power factor correction. 


\section{CONCLUSIONS}

This paper introduces both simulation results and experimental results for three-phase APF at two different non-linear load types. The harmonics extraction algorithm is based on the Average Control Technique on the $d-q$ reference frame. The closed loop system is implemented using the hysteresis current controller. It is clear from the results obtained that harmonic current extraction has been accomplished successfully. Good results has been achieved for both harmonics compensation and power factor correction.

\section{REFERENCES}

[1] Bhim Singh, Kamal Al_Haddad, And Ambrish Chandra. "A Review of Active Filters for Power Quality Improvement" IEEE Trans. Ind. Elect, Oct. 1999., Vol. 46, No. 5 pp 960-971.

[2] M.EI-Habrouk, M.K.Darwish And R. Mehta "Active power filters: A review" IEE Proc.-Electr.
Power Appl., Sept. 2000, Vol. 147, No. 5, Pp. 403413.

[3] Akagi H., Kanazawa Y., And A. Nabae. “ Instantaneous Reactive Power Compensators Comprising Switching Devices without Energy Storage Components " IEE Trans. On Ind. Appl., May/June 1984, Vol. IA-20, No. 3, pp. 625-630.

[4] Seung-Gi Jeong and Myung-Ho Woo," DSPBased Active Power Filter With Predictive Current Control ", IEEE Trans. Ind. Electron., Vol. 44, June 1997, pp. 329-336.

[5] M.EI-Habrouk, M.K.Darwish And Rmehta, "Active power filters: A review", IEE Proc. - Electr. Power Appl. Vol. 147, No. 5, Sept. 2000, pp. 403413.

[6] B.N.Singh, A.Chandra And K.AI-Haddad, "DSPbased indirect-current-control led STATCOM Part 1: Evaluation of current control techniques" , $\mathbb{E E E}$ Proc. - Electr. Power Appl. Vol. 147, No. 2, March 2000, pp. 107-112. 